\title{
A Pathway to Small Satellite Market Growth
}

\author{
Anders Kose Nervold1, Joshua Berk², Jeremy Straub3, David Whalen² \\ ${ }^{1}$ Department of Entrepreneurship, University of North Dakota, Grand Forks, USA \\ ${ }^{2}$ Department of Space Studies, University of North Dakota, Grand Forks, USA \\ ${ }^{3}$ Department of Computer Science, University of North Dakota, Grand Forks, USA \\ Email: anders.nervold@my.und.edu, joshua.berk@my.und.edu, jeremy.straub@my.und.edu, \\ whalen@space.edu
}

Received 24 May 2016; accepted 24 June 2016; published 27 June 2016

Copyright (C) 2016 by authors and Scientific Research Publishing Inc.

This work is licensed under the Creative Commons Attribution International License (CC BY). http://creativecommons.org/licenses/by/4.0/

(c) (i) Open Access

\section{Abstract}

The United States is experiencing a renaissance in interest in space due to the advent of new lowercost small spacecraft. New launch entrants, such as Interorbital Systems, promise to lower launch cost levels. Many developers also benefit from free-to-developer launch services from NASA or the ESA. Unfortunately, existing commercial off the shelf (COTS) CubeSat hardware is priced based on amortization of design costs across low-sales volume. A lack of trained staff in any one of the numerous disciplines required for spacecraft design or other resources required for in-house development restricts entry into the small satellite industry to those who can afford expensive COTS hardware or pay for significant design expenses. With entry-level satellite hardware still priced in the six-figure range, limited market growth is expected even as the average CubeSat launch cost continues to decline. A new archetype could lower barriers to entry for building small satellites. A free, public-domain architecture for building a small satellite could allow low-cost, in-house satellite development. Under this paradigm, the expenses for initiating a small satellite program are limited to component and launch vehicle costs. The proposed framework allows for broad access to small satellite hardware, greatly increasing the size of the small satellite developer community. In the context of the small satellite market, freely offering plans to construct an entry-level satellite will court new non-traditional actors into building space hardware for launch on commercial and government small satellite launchers. The low-cost, high flight rate possible with the next generation of launch systems affords operators the freedom to experiment and innovate in a risktolerant environment. Successfully demonstrating products and services utilizing low-risk, publicdomain plans will stimulate demand for mature and more capable flight systems in the retail marketplace. If technical schools, community colleges, universities, small businesses and even amateurs can enter into the small satellite ecosystem, at an affordable entrance price, a positive spiral of increasing demand and decreasing cost may be created over time. A free, public domain satellite architecture may, thus, open the door to sustained growth and commercial opportunity for the small satellite industry. 


\section{Keywords}

\section{CubeSat, Small Spacecraft, Educational Economics, Market Growth}

\section{Introduction}

CubeSats serve as excellent tools to aid in education and the development of experience in the space domain. Not only can students, professionals, and amateurs get a chance to gain first-hand knowledge about designing and building a spacecraft, but they can also engage in space mission design and operations. To date, a few thousand students have been involved in the development and launch of over 50 cube satellites in the last 15 years [1]. While this is ample reason to call CubeSats an educational success, the fact of the matter is that the relative high cost of developing CubeSats acts as a barrier to entry.

There are a plethora of students, professionals, businesses, and amateurs that might want to engage in the space industry, through low-cost satellites, but they are currently faced with three major obstacles.

\subsection{High Launch Costs in the Continental US}

While it is cheaper to launch a CubeSat on a Russian rocket [2], export controls, in the form of ITAR regulations, make it difficult to launch a US developed satellite abroad. Student teams and university researchers are currently getting around the high launch cost problem by being a secondary payload on federal government funded launches, essentially getting a free ride to space, under NASA's Educational Launch of nanosatellites Program (ElaNa) or the ESA's "Fly Your Satellite" Program. As a result of being a secondary payload on a federally funded launch, the teams do not get to pick the time of the launch, nor the elevation and inclination of their $\mathrm{Cu}$ beSats' orbit. Rather, they choose a range of acceptable parameters, and wait until there is space available on a government rocket for them to launch. In addition to this, ELaNa is only available to teams meeting certain criteria [3]. These restrictions lead to uncertainty in the design of the CubeSat, and reduced effectiveness in meeting the CubeSat's scientific objective.

\subsection{High Development Costs}

It is expensive to develop a CubeSat. Most of the components are typically custom-fabricated or purchased from commercial off the shelf (COTS) vendors, both of which are expensive. In addition to this, the design, development, and construction of a typical CubeSat requires several thousand work hours of trained individuals. While students generally perform this labor on a volunteer basis or for class credit for their University sponsored CubeSat research projects, the level of labor required acts as a significant barrier to entry for professionals, businesses, and amateurs. The typical CubeSat costs between $\$ 50,000$ and $\$ 200,000$ to develop in a University setting as described above [4].

Several US-based commercial enterprises have announced their plans for significantly lowering the cost of launching small and nanosatellites to low-Earth-orbit (LEO). Whereas right now, it is reasonable to assume launch costs of around $\$ 50,000$ to $\$ 200,000$ for a CubeSat [5], Boeing, Interorbital Systems, Lockheed Martin, SpaceX, and Virgin Galactic, have all announced plans that can reduce this estimate to between $\$ 10,000$ and $\$ 85,000$ by 2020 [6] [7]. Additionally, Congress has recently completed a modification to the ITAR regulations that could make it significantly easier to launch a US developed satellite abroad [8]. Many CubeSat have already been launched on re-purposed Russian ICBMs, at prices as low as $\$ 10,000$ a piece [2]. The ITAR changes could make it easier for the same to happen with educationally built satellites.

With these commercial and federal efforts in the works to re-duce the cost of launching a CubeSat, it is reasonable to assume that launch costs will be drastically reduced in the next few years. Presuming a successful outcome of these efforts, a situation is likely to develop where the costs of developing a CubeSat remains disproportionately high compared to launch costs.

It is generally believed [e.g.], [9] that construction of CubeSats (and consequentially the demand for launches) will not increase significantly unless there is a significant reduction in the development cost of CubeSats. Swartwout [9] notes that even pro-grams that have developed an initial spacecraft (developing and demonstrat- 
ing the requisite competence) in many cases cannot afford to build a second one. It is important to reduce $\mathrm{Cu}-$ beSat and other nanosatellite costs for two important reasons: First, the emerging industry of low cost launches for smaller form factor satellites are dependent on increased demand for launches of such payloads for commercial success and viability. Second, it is important to lower the barrier to entry in the Space industry so that all those that want can get the proper experience and education needed to pursue careers and/or research innovation in the space domain. This is essential for continuous innovation and commercialization in the space industry.

While several alternatives for dramatically reducing development costs of small form factor satellites should be explored, this paper will focus on one such alternative currently being developed at the University of North Dakota.

The Open Prototype for Educational NanoSats (OPEN), is a collection of public domain resources that includes all of the documentation, schematics and other reference material needed to build a capable CubeSat. The OPEN standard will include an innovative way of structuring the components inside the CubeSat to yield more room for the satellite's payload than what is normally achieved.

Not only will OPEN dramatically reduce the number of work hours required to design, develop and construct a CubeSat, by an estimated factor of as much as 50 (e.g., from $\$ 250,000$ to $\$ 5000$ in a worst-case to best-case scenario), it will also dramatically reduce the cost of the overall system to the point where university teams should be able to build their own CubeSat, payload excluded, for a parts cost of under $\$ 5000$.

This paper details how OPEN contributes to the cost-reduction of nanosatellites, and indicates recommendations for further study to achieve this sought after price elasticity of demand.

\section{The Cost Dilemma}

Satellites have historically had a cost structure that was divided in to two roughly equal parts: launch costs, and development costs. Communication satellites are becoming increasingly complex, and increasingly larger, which has led to development costs that are starting to far exceed the launch costs [10].

Nano-satellites like CubeSats, tend to have a different cost structure, where roughly $1 / 3$ of the real cost of the entire satellite can be attributed to launch costs and 2/3 can be attributed to development costs. The cost structure and its implications will now be explored.

\subsection{Launch Costs for CubeSats}

CubeSat developers tend to have two options when it comes to launching their satellite to orbit. The first option is to get a governmental agency to sponsor the launch, typically on a launch vehicle with a larger agency payload. The other option is to identify a commercial provider of launches, and pay the provider's price. There are benefits and drawbacks to both options.

Government sponsored launches, while considered "free" in the sense that there is no billing of actual cash occurring between the "provider" and the "customer", are typically the most limiting. The CubeSat that is being launched on a government-sponsored launch is usually a secondary payload in a vehicle that carries a larger, more complex, and more expensive satellite [11]. This dictates a plethora of restrictions designed to protect the primary payload.

A limiting factor of being a secondary payload, is the lack of control in choosing a launch date, the orbital elevation and the orbital inclination of the CubeSat. The CubeSat developers typically choose a range of parameters that they can accept and provide these to the space agency that will launch the craft. For ex-ample, the developers may request an elevation of between 350 - $450 \mathrm{~km}$, and an inclination of between 45 and 65 degrees. The space agency will then attempt to match this payload up to a future launch that will carry a primary payload to an orbit within this range [3]. The more specific, or less common the parameters, the longer the potential wait period becomes. This can result in delays of up to several years or result no launch occurring at all, in a worstcase scenario. Inherently, there is a trade-off between how specific the orbit needs to be for its scientific objective versus the duration of wait that the developers find acceptable before having their CubeSat launched.

Government sponsored launches are typically reserved for CubeSats that are being developed by a space agency or by students and faculty at research institutions or other non-profits [12]. Commercial launches allow CubeSat developers more flexibility in choosing their launch date, orbital elevation, and orbital inclination, but require payment for the launch services.

In 2003, a resegmentation of the nanosatellite launch market occurred when Russian companies dramatically 
reduced the launch costs for these small factor satellites [2]. By repurposing old ICBMs, these Russian companies were able to offer launch services for CubeSat at a dramatically lower price than any competitors. Prices were quoted in the $\$ 10,000$ to $\$ 50,000$ range and, as a result, universities and companies alike flocked to the new Russian providers [2].

Where launches of CubeSats prior to 2003 were far between and uncommon, the Russian resegmentation of the market in-creased played a role in increasing the demand for CubeSat launch services. As demonstrated in Table 1, over 49\% of the CubeSat launch services provided in the years 2003 to 2011 were provided by commercial enterprises.

Commercial launch services for CubeSats, in addition to their higher cost, carry a higher risk factor. Between 2003 and 2011, a total of 12 launch vehicles carried CubeSat payloads. Four of these were commercial, and 8 of which were government sponsored. Of the 4 commercial launches, 2 were declared complete failures, as the CubeSat payloads never reached orbit, and were lost. The first of these launch failures occurred on a repurposed Russian ICBM in 2006, where 14 CubeSats were declared lost. The other failure occurred with a US Falcon 1 rocket launch in 2008, operated by SpaceX Inc, where 2 CubeSats were declared lost [1].

Although launch costs have declined significantly in Russia, the rest of the market lags behind. Some US based companies have realized that there is a market for lower cost launches for smaller satellites, and have, as such, published plans about up-coming services they plan to offer.

These include Boeing, with their Small Launch Vehicle slated for a market debut in 2020; Interorbital Systems, with their Neptune rocket series originally slated for a market debut in 2011, but which has been postponed indefinitely; Lockheed Martin, with a ride-share system on their revived Athena rocket program slated for a market debut in 2014; and Virgin Galactic, with their Launcher One vehicle slated for a market debut in 2016. Accurate Based the information currently available, it is reasonable to assume that a CubeSat launch can be purchased for as little as $\$ 10,000$ to $\$ 85,000$ in the near future [6].

\subsection{Development Costs for CubeSats}

While a decrease in average price has occurred in the launch services of CubeSats, the same does not hold true for the development costs for a CubeSat. Current cost estimates are still roughly the same as they were 10 years ago. Most sources estimate this cost at $\$ 50,000$ to $\$ 250,000$ depending on the complexity of the CubeSat, the type of payload, and scope of operations of the CubeSat [4]. This estimated cost is the sum of actual cash spent on the project to have a one-unit CubeSat de-signed, developed, and built. There are however some issues with looking at the costs this way.

Many CubeSats that have been launched have been designed, developed, and constructed in educational institutions. While the actual cash spent on the project contributes to overall costs, it is not a comprehensive estimate.

Table 1. CubeSat Launches per Year [1].

\begin{tabular}{ccc}
\hline Year & \# Launched & \# Commercial \\
2003 & 6 & 6 \\
2004 & 0 & 0 \\
2005 & 3 & 0 \\
2006 & 16 & 14 \\
2007 & 7 & 7 \\
2008 & 8 & 2 \\
2019 & 4 & 0 \\
2010 & 3 & 0 \\
2011 & 12 & 0 \\
Total & $\mathbf{5 9}$ & $\mathbf{2 9}$ \\
\% & $\mathbf{1 0 0 \%}$ & $\mathbf{4 9 \%}$ \\
\hline
\end{tabular}


It usually only encompasses direct costs, such as the various component costs, shipping costs and tools and supplies needed to do the project. It is obvious that three major costs are lacking in this cost equation: 1) Insurance of the payload (if purchased), 2) Laboratory and existing equipment costs, and 3) Labor costs.

Per international agreement, the responsible national government is completely liable for the damage their spacecraft causes as a result of having been present in an orbit around the Earth. For instance, if country A's satellite crashes into country B's satellite, country A is responsible for all damages and compensation to satellite B's owner. Satellites can vary in value between $\$ 50,000$ and $\$ 2,000,000,000$ and, although crashes have happened between satellites, they are rare. Also, if satellite A was to deorbit and return to the Earth's surface, country A would be liable for any and all damage it caused upon re-entry and "landing" [11].

Governments around the world deal with these liabilities in various ways. In some countries, like the United States, the government assumes the risk of loss without underwriting for its sovereign spacecraft, while if a private company were to send up a spacecraft, the government may require some sort of insurance [13]. The insurance cost is difficult to estimate, but for educational institutions as well as some companies, such liability damage may be covered (or coverage added) under their liability insurance.

In a university or commercial setting, resources and equipment may be accessed at no direct cost to the project. For amateurs and small businesses, gaining access to these facilities can be a barrier to entry. The actual cost of such resources is hard to estimate, varying both by the scope of the project, the complexity of the CubeSat. There can, however, be no doubt that these costs can be substantial.

Finally, the cost of labor must be considered. In a university setting, most of the work done to design, develop, and construct a CubeSat will be performed by students participating in the project. In some cases this work done for class credit; in many cases there is no reward other than the experience gained.

Most businesses on the other hand do not have this luxury, as they will have to pay for all labor. Labor costs will certainly vary a lot from project to project, dependent on variables such as the scope of project, the complexity of the CubeSat, the type of pay-load, the life span of the project, as well as whether the project is conducted in a business or university setting.

By considering a CubeSat project at a research university, one can gain an understanding for the scope of labor costs. From 2001 to 2006, the University of Illinois at Urbana-Champaign developed their ION CubeSat. During this 5-year project, over 100 students participated in the design, development, and construction of their CubeSat [14].

In this case, many of the engineering students participated in exchange for class credit. At this university, one credit hour requires 45 lab hours per semester [14]. Assuming that the typical student enrolls in classes averaging 3 credit hours, each participating student would be required to put 135 hours per semester into the project. For this analysis, it will be assumed that students not participating for class credit yielded the same level of involvement. This equates to about 8.5 hours per week per student.

Additionally, there were weekly meetings, and it can be inferred from [14] that these meetings were in addition to the lab participation. It can be assumed that 2 hours per week per student were spent in project meetings [14].

By assuming that 100 students participated for one academic year, totaling 32 weeks, at a rate of 10.5 hours per week, such a CubeSat project would require a total of 33,600 skilled labor work hours. Such skilled labor, while in a student setting is certainly less costly than in a professional setting, it is still moderately above minimum wage. By assuming an hourly rate of $\$ 12.50$, the total labor costs for this project would have been $\$ 420,000$. This figure is quite staggering when compared to the actual cash outlays of the project. This most certainly acts as an incredible barrier to demand for businesses.

\section{The OPEN Solution}

Although the launch costs of a typical CubeSat may have come down, possibly by as much as a factor of 5 , the net effect in actual cost is not that obvious. If other factors are considered (as described in section 2), this reduction becomes rather insignificant. By refereeing to Table 1, it can be observed that there has not been a significant increase in demand for CubeSat launch services in the last 10 years. To achieve demand growth in the years to come, total mission cost must be reduced.

To foster growth in CubeSats, a similar drastic cost reduction needs to be achieved in the developmental side of the cost structure. A project called Open Orbiter at the University of North Dakota is currently working on a 
solution to this dilemma, called the Open Prototype for Educational NanoSats (OPEN).

OPEN presents a solution to the barrier-to-entry problem faced by aspiring entrants into the small satellite development space. Previous to OPEN, these entrants were forced to choose between either developing a spacecraft from scratch or purchasing a vendor-kit (or ad-hoc kit of compatible components).

In the former case, the entrant would incur significant design costs. These would include the cost of designing the structure, bus and subsystems of the satellite and associated test and operations plans. The entrant, under this scenario, would have a significantly lower cost basis for any future similar spacecraft that they sought to produce (comprised of component, fabrication and testing costs). Alternately, under the second scenario, the prospective entrant would not incur as high of an entry cost (perhaps one-third to one-fifth, depending on situationspecific factors); however, they would continue to re-incur this cost for future spacecraft (unless and until they undertook to develop their own designs and plans).

Some prospective entrants (including many educational institutions) are not able to afford either of the aforementioned entry paths. These entrants, thus, would find the barrier to entry impermeable.

OPEN makes small satellite development affordable to most if not all educational institutions on a cost-basis in-line with what they incur for other student learning activities (e.g., NASA's Lunabotics). This cost level (approximately $\$ 5000$ in hard-ware and fabrication costs for a base configuration) can, generally, be met from student equipment and instructional funds. Moreover, this reduced cost basis makes small satellites more accessible for use in research projects. The availability of plans allows users to make small, moderate or even major changes with a known-good starting point. This is, generally, not possible with vendor equipment. In many cases, even a small change incurs significant design, redevelopment and/or licensing costs.

By providing public domain reference material that will allow other institutions, businesses and amateurs to construct a CubeSat for less than $\$ 5000$, a similar significant cost reduction is observed in the actual cash cost of this type of project.

By reducing the required level of design and developmental work, overall labor hours are cut by a substantial amount, although not quite the same factor that hardware costs and launch costs were reduced by. It is difficult to estimate exactly what kind of impact it will have, but it will comprise a dramatic reduction in labor time needed. It removes design costs, aside from the payload, and it reduces testing and integration costs because the documentation for those will be provided.

If typical costs are considered for a CubSat project in an educational institution, excluding launch costs, they can be lowered from a range of $\$ 50,000$ to $\$ 250,000$ to a range of $\$ 5000$ to $\$ 50,000$. Not only should this allow for more CubeSat projects at research universities, but is should also significantly lower the barriers to entry by smaller universities, colleges, technical schools, and high schools that cannot support expensive research projects such as todays' CubeSat projects.

\section{Conclusions}

Though dramatic decreases in the average launch cost of a CubeSat has been observed (due to a combination of decreasing cost levels overseas, free-to-developer government-furnished launches and new commercial entrants), the cost of developing a CubeSat has held relatively stagnant over the past 15 years.

To significantly lower the barriers to entry for CubeSat projects, a similar level of cost reduction needs to be realized in the developmental side of the cost structure. The OPEN framework that is being developed at the University of North Dakota, is aiming to do just that by providing reference material that will allow for the construction of a CubeSat for as little as $\$ 5000$.

While demand has held rather stagnant over the past 10 years, this new dramatic cost reduction could make entry possible by educational institutions, firms and individuals that previously were prevented from participating. This could create a surge in demand, creating a beneficial spiral of price reduction.

\section{Acknowledgements}

Small spacecraft development work at the University of North Dakota is or has been supported by the John D. Odegard School of Aerospace Sciences, North Dakota EPSCoR, the North Da-kota Space Grant Consortium, North Dakota NASA EPSCoR, the UND Department of Computer Science and the National Aeronautics and Space Administration. 


\section{References}

[1] Konstantinidis, K., N.d. Cubesats: A Review. http://www.thesciencecollective.com/ctide/wp-content/uploads/2011/11/Cubesats a review KKonstant.pdf

[2] RussianSpaceWeb.com. N.d. The Dnepr Launcher. http://www.russianspaceweb.com/dnepr.html

[3] Skrobot, G. (2012) ELaNa—Education Launch of Nanosatellite Providing Routine RideShare Opportunies. Proceeding of the SmallSat Conference.

[4] Straub, J. (2012) CubeSats: A Low-Cost, Very High-Return Space Technology. Proceedings of the AIAA Reinventing Space Conference.

[5] SpaceFlight Services. N.d. http://spaceflightservices.com/pricing-plans/

[6] Interorbital Systems. N.d. http://www.interorbital.com

[7] Norris, G. (2012) Low-Cost Launcher. Aviation Week \& Space Technology, 174, 25.

[8] Lovells, H. (2011) Congress Authorizes Easing of U.S. Export Control Applicable to Commercial Communications Satellites. http://www.lexology.com/library/detail.aspx?g=60a629dc-d016-477c-9414-432b8b98557b

[9] Swartwout, M. (2011) AC 2011-1151: Significance of Student-Built Spacecraft Design Programs It's Impact on Spacecraft Engineering Education over the Last Ten Years. Proceedings of the American Society for Engineering Education Annual Conference.

[10] CubeSat.org. N.d. www.cubesat.org

[11] (1967) The Outer Space Treaty.

[12] National Aeruonautics and Space Administration (2012) Announcement of CubeSat Launch Initiative. http://www.nasa.gov/pdf/627968main_CSLI_Announcement_of_Opportunity_11_2_2012.pdf

[13] Persaud, S. (2012) Regulatory Matters Concerning Authorization of Small Sats. 2012 Summer Cubesat Workshop.

[14] Thakker, P. and Shiroma, W.A. (2010) "Management and Implementation of a Cubesat Interdisciplinary Senior Design Course” in Emergence of Pico-and Nanosatellites for Atmospheric Research and Technology Testing. AIAA, Reston, 17-32.

\section{Submit or recommend next manuscript to SCIRP and we will provide best service for you:}

Accepting pre-submission inquiries through Email, Facebook, Linkedin, Twitter, etc A wide selection of journals (inclusive of 9 subjects, more than 200 journals)

Providing a 24-hour high-quality service

User-friendly online submission system

Fair and swift peer-review system

Efficient typesetting and proofreading procedure

Display of the result of downloads and visits, as well as the number of cited articles

Maximum dissemination of your research work

Submit your manuscript at: http://papersubmission.scirp.org/ 